\section{Hemagglutinating Encephalomyelitis Coronavirus Infection in Pigs, Argentina}

\author{
María A. Quiroga, ${ }^{*}$ Javier Cappuccio, ${ }^{*}$ \\ Pablo Piñeyro, ${ }^{*}$ Walter Basso, ${ }^{*}$ Gastón Moré, ${ }^{*}$ \\ Mariana Kienast, $\dagger$ Sergio Schonfeld, $\ddagger$ \\ José L. Cáncer,ł Sandra Arauz, ${ }^{*}$ María E. Pintos, ${ }^{*}$ \\ Mariana Nanni, $\dagger$ Mariana Machuca, ${ }^{*}$ \\ Norio Hirano,§ and Carlos J. Perfumo*
}

We describe an outbreak of vomiting, wasting, and encephalomyelitis syndrome in piglets in Argentina, caused by porcine hemagglutinating encephalomyelitis coronavirus (PHE-CoV) infection. Diagnosis was made by epidemiologic factors, pathologic features, immunohistochemistry, reverse transcription-PCR, and genomic sequencing. This study documents PHE-CoV infection in South America.

$\mathrm{P}$ orcine hemagglutinating encephalomyelitis (PHE) is an infectious disease that primarily affects pigs $<3$ weeks of age (1). The disease is caused by PHE coronavirus (PHE$\mathrm{CoV}$ ) (2), which comprises a single strain and is the only known neurotropic $\mathrm{CoV}$ for pigs (3-5).

PHE-CoV was first isolated in Canada from the brains of suckling piglets with encephalomyelitis (6); it was later isolated in England from piglets exhibiting vomiting, anorexia, and depression, where it was named "vomiting and wasting disease" (VWD) (7). Neurologic and digestive characteristics of the disease were experimentally reproduced in pigs by using the same field virus isolate (8). The infection has been reported in the major pig-raising countries of Europe, Asia, and North America, where it seemed to be endemic with no clinical outbreaks $(7,9,10)$.

Presumptive diagnosis can be made by correlating epidemiologic data, age susceptibility information, and disease course with histopathologic findings $(3,10)$. For definitive diagnosis, the virus should be isolated and identified (3). Currently, immunohistochemical (IHC) tests for PHE-CoV or molecular tools such as reverse transcription-PCR (RTPCR) enable specific CoV RNA sequences to be detected from infected tissues $(11,12)$. We describe a PHE-CoV out-

*Universidad Nacional de la Plata, La Plata, Argentina; †Centro de Investigaciones en Ciencias Veterinarias, Castelar, Argentina; $\ddagger$ Private practice, Roque Perez, Argentina; and §lwate University, Morioka, Japan break in an intensively managed farm in Argentina as well as the techniques applied for diagnosis.

\section{The Study}

The farm was a 3 -site herd with a total of 6,000 sows. At the time of the outbreak, $55 \%$ of breeder stock were gilts or first- or second-parity sows. Site 1 comprised 20 gestation barns and 19 farrowing barns, site 2 (nursery) comprised 9 barns, and site 3 comprised growing and fattening barns.

The outbreak began on August 8 and ended on August 23, 2006. Of 19 farrowing barns, $10(52.6 \%)$ were affected. Total proportion of deaths in pigs that had not been weaned was $16.9 \%$ (1,226 dead pigs); an estimated $12.6 \%$ of pigs that died had suspected PHE-CoV infection (913 animals).

Clinical signs were observed in pigs $\geq 4$ days of age and consisted of vomiting, listlessness, pallor, and dehydration. Neurologic signs such as abnormal gait, dullness, inability to eat, tremors, and nystagmus were observed in some animals. Vomiting and wasting occurred in $27.6 \%$ of pigs $\leq 1$ week of age and gradually declined to $1.6 \%$ in pigs 3 weeks of age (mean 13.6\%). Twenty-nine percent of weaned pigs housed in nursery barns that received affected animals from site 1 showed wasting (Figure 1, panel A), and the proportion of deaths was $15 \%-40 \%$. In total (sites 1 and 2), 3,683 piglets died or were euthanized.

Postmortem examinations were performed on 16 affected piglets, 2-11 days of age. Samples submitted for histopathologic examination included brainstem, trigeminal ganglia, tonsils, pyloric gland area of the stomach,
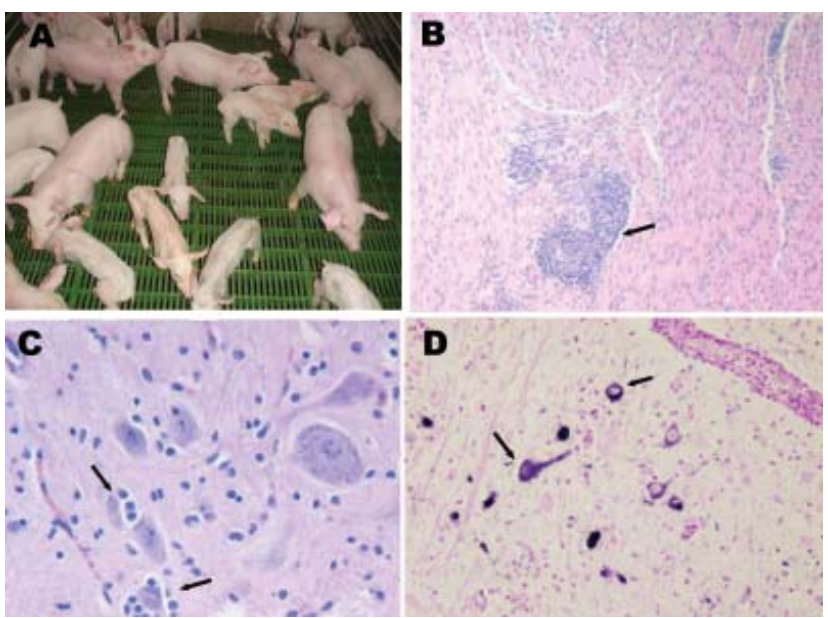

Figure 1. A) Nursery piglets showing clinical signs compatible with porcine hemagglutinating encephalomyelitis coronavirus (PHE-CoV). Nonaffected pigs of the same age are also shown. B) Muscle layer of stomach from affected piglet showing perivascular cuffing (arrow); hematoxylin-eosin stain, magnification $\times 100$. C) Brainstem from affected piglet showing satellitosis (arrows) and gliosis; hematoxylineosin stain, magnification $x 400$. D) Brainstem from affected piglet showing positive label of neuron perikarion (arrows); nitrobluetetrazolium imunohistochemical stain, magnification $\times 400$. 
jejunum, ileum, lymph nodes, heart, spleen, liver, kidneys, and lung.

Selected paraffin sections of brainstem from 5 piglets that had characteristic microscopic lesions were examined for PHE-CoV antigen by IHC tests with an anti PHECoV-67N strain mouse antibody; the samples were diluted $1: 1,000$ and incubated overnight at $4^{\circ} \mathrm{C}$. Samples were then labeled with biotinylated conjugated anti-mouse immunoglobulin $\mathrm{G}(\mathrm{IgG})$ goat antiserum at room temperature for 2 $\mathrm{h}$. The color reaction was detected by alkaline phosphatase and 5-bromo-4-chloro-3-indoyl phosphate by using nitroblue-tetrazolium and true red as cromogens.

RNA was isolated with a commercial kit (RNeasy, QIAGEN GmbH, Hilden, Germany), from brain samples of 7 symptomatic piglets (6-11 days of age) that had nonsuppurative encephalomyelitis, from 1 asymptomatic piglet, and from a PK-15 cell culture suspension inoculated with a pool of tissues from 1 symptomatic piglet. Ribonuclease-A (RNase)-free water was used as negative control. The RT-PCR was performed immediately after RNA isolation by using the specific primer pair for $\mathrm{CoV}$, Cor-FW $5^{\prime} \rightarrow 3^{\prime}$ (DNA) ACTCAAATGAATTTGAAATATGC, and Cor-RV $5^{\prime} \rightarrow 3^{\prime}$ (DNA) TCACACTTTGGATAA TCCCA that amplifies a 251-bp fragment of the polymerase gene (11). The reaction was performed in a total volume of 50 $\mu \mathrm{L}$ containing $2 \mu \mathrm{L}$ RNA extract, $10 \mu \mathrm{L} 5 \times$ QIAGEN OneStep RT-PCR buffer, $2 \mu \mathrm{L}$ dNTPs mix (final concentration of $400 \mu \mathrm{mol} / \mathrm{L}$ of each dNTP), $1.8 \mu \mathrm{L}$ QIAGEN OneStep RT-PCR Enzyme Mix, $4 \mu \mathrm{mol} / \mathrm{L}$ of each primer and RNase-free water to $50 \mu \mathrm{L}$. The reaction was conducted in a thermal cycler (PCR Sprint Thermo Electron Corp., Waltham, MA, USA) with an initial reverse transcription at $50^{\circ} \mathrm{C}$ for 30 -s activation at $95^{\circ} \mathrm{C}$ for $15 \mathrm{~s}, 40$ cycles of amplification $\left(30 \mathrm{~s}\right.$, at $94^{\circ} \mathrm{C}, 30 \mathrm{~s}$ at $50^{\circ} \mathrm{C}$, and $1 \mathrm{~min}$ at $\left.72^{\circ} \mathrm{C}\right)$, and a final extension step at $72^{\circ} \mathrm{C}$ for $10 \mathrm{~min}$.

The amplicons were purified by using the QIAquick PCR purification kit (QIAGEN) and sequenced on a MegaBase 1000 DNA sequencer (GE Healthcare, Chalfont St. Giles, UK). The obtained sequence was analyzed by using NCBI BLAST (www.ncbi.hlm.hig.gov).

Virus isolation was attempted by inoculation of PK-15 and SK-K cells with brains and tonsils from 5 pigs positive for PHE-CoV by RT-PCR. Five blind passages were performed at 7-day intervals. IHC testing was also performed on SK-K cells.

Microscopic changes were observed in samples taken from 5- to 11-day-old affected pigs. The most remarkable changes were perivascular cuffing around Meissner and Auerbach ganglia in the muscle layer of stomach (Figure 1, panel B), ganglioneuritis in the trigeminal ganglion, and nonsuppurative encephalomyelitis (Figure 1, panel C). PHE-CoV-positive neurons were found in the brainstem (Figure 1, panel D) and trigeminal ganglion.
RT-PCR analysis showed a product of the expected size for $\mathrm{CoV}(\approx 250 \mathrm{bp})$ in all analyzed brain samples. No amplification was observed in inoculated PK 15 cells (Figure 2). The relationship between clinical course, lesions, and IHC and RT-PCR results is shown in the Table. A constant 116nt sequence was obtained for all products amplified from symptomatic piglets and submitted to GenBank (accession no. EF602436). The sequence showed a 95\% identity with the complete genome of PHE-CoV strain VW572 (accession no. DQ 011855) and with PHE-CoV RNA-directed RNA polymerase gene (accession no. AF 124988). Detection of amplicons of $\approx 250 \mathrm{bp}$ with "pancoronavirus" primers in brain samples is highly suggestive of the presence of PHE-CoV. Sequence analysis confirmed this observation. Cytopathic effects were not observed, and PHE-CoV antigens were not detected in inoculated cells.

\section{Conclusions}

From an epidemiologic standpoint, the clinical course of the disease (3 weeks), age of affected pigs ( $<3$ weeks), and clinical signs were in agreement with those of VWD caused by PHE-CoV (3,8,13). On PHE-CoV-endemic farms, immune sows apparently provided immunity to their offspring through colostrum (3), and clinical disease seldom occurred. In our study, because the gilt pool was so large, a nonimmune subpopulation very likely existed and might have acted as a potential source of virus multiplication. The severity of clinical signs such as vomiting, emaciation, wasting, and death was greater than that previously reported (10). Factors that might have enhanced the clinical manifestations of the disease were a nonimmune population and the winter season $(3,8,10)$.

Pensaert (3) reported perivascular cuffing and neuronal degeneration at the intramural nervous plexus of the stomach in pigs showing VWD. In addition, Pensaert (3)

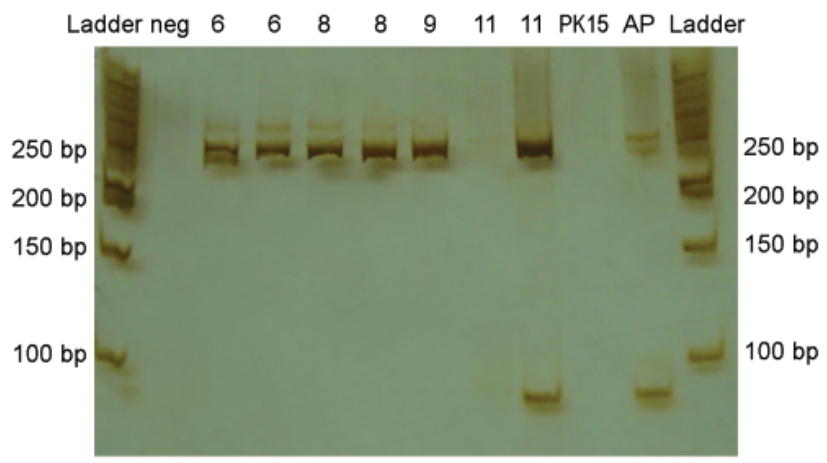

Figure 2. Polyacrylamide gel and silver staining of reverse transcription-PCR products from brains of piglets infected with porcine hemagglutinating encephalomyelitis coronavirus. Amplicons of $\approx 250$ bp were found in brain samples from pigs 6,8 , 9 , and 11 days of age. Neg, negative control (water + mastermix); PK15, amplification of PK15 cells inoculated with brain and tonsil from affected piglet; AP, asymptomatic piglet; and Ladder, 50-bp Fermentas. 


\section{DISPATCHES}

Table. Clinical signs and results of histopathologic examination, IHC testing, and RT-PCR from piglets affected by PHE-CoV*

\begin{tabular}{lcccc}
\hline Organ & Days old (days with clinical signs) & IHC & RT-PCR & Histopathologic diagnosis \\
\hline Brain stem & $6(2)$ & + & + & Encephalitis \\
Brain stem & $8(4)$ & + & + & Encephalitis \\
Trigeminal ganglion & $8(4)$ & + & + & Focal ganglioneuritis \\
Brain stem & $8(4)$ & ND & ND & Encephalitis \\
Spinal cord & $9(5)$ & ND & ND & Myelitis \\
Tonsil & $9(5)$ & ND & ND & Necrotizing tonsilitis \\
Brain stem & $9(5)$ & + & + & Meningoencephalitis \\
Medulla oblongata & $11(6)$ & Meningoencephalitis \\
\hline
\end{tabular}

*IHC, immunohistochemical; RT-PCR, reverse transcription-PCR; PHE-CoV, porcine hemagluttinating encephalomyelitis coronavirus; ND, not done; + , positive.

described nonsuppurative encephalomyelitis in 70\%-100\% of animals showing neurologic signs and in $20 \%-60 \%$ of animals with VWD syndrome. In our study, nonsuppurative encephalomyelitis was found in $50 \%$ of infected animals. Our IHC results agreed with findings reported by others in which $\mathrm{CoV}$ antigen was detected only in neurons $(8,14,15)$. Detection of amplicons of $\approx 250 \mathrm{bp}$ in brain samples was highly suggestive of PHE-CoV because this is the only known neurotropic $\mathrm{CoV}$ for pigs (4). In addition, results observed in samples of nervous tissue processed for IHC, RT-PCR, and sequence analysis added further evidence of the precise causal agent of the current outbreak. This report documents the emergence of PHE-Cov in South America.

\section{Acknowledgments}

We thank Carolina Aralda and Lorena Diaz for their valuable help with making histopathologic slides and Magdalena Rambeaud for assistance with English translation.

This work was supported by grants from Fondo para la Investigación Científica y Tecnológica 05-33987, Secretaría de Ciencia y Técnica, Universidad Nacional de La Plata, and Pacuca Pig Farm SA, Argentina.

Dr Quiroga is a doctor of veterinary medicine at Universidad Nacional de la Plata, Argentine. Her main areas of interest are emerging viral diseases of pigs, including circovirus type 2 and coronavirus.

\section{References}

1. Chang GN, Chang TC, Lin SC, Tsai SS, Chern RS. Isolation and identification of hemagglutinating encephalomyelitis virus from pigs in Taiwan. J Chin Soc Vet Sci. 1993;19:147-58.

2. Greig AS, Johnson CM, Bouillant AMP. Encephalomyelitis of swine caused by haemagglutinating virus. VI. Morphology of the virus. Res Vet Sci. 1971;12:305-7.

3. Pensaert MB. Hemagglutinating encephalomylitis virus. In: Straw BL, Zimmerman JJ, D'Allaire S, Taylor DJ, editors. Diseases of swine, 9th ed. Ames (IA): Blackwell Publishers; 2006. p. 353-8.
4. Sasseville AM, Boutin M, Gélinas AM, Dea S. Sequence of the 3'terminal end $(8.1 \mathrm{~kb})$ on the genome of porcine haemagglutinating encephalomyelitis virus: comparison with other hemagglutinating coronaviruses. J Gen Virol. 2002;83:2411-6.

5. Greig AS, Girard A. Serological comparison of hemagglutinating encephalomyelitis viruses isolated from different outbreaks. Can J Comp Med. 1969;33:25-8.

6. Greig AS, Mitchell D, Corner AH, Bannister GL, Meads EB, Julian RJ. A hemagglutinating virus producing encephalomyelitis in baby pigs. Can J Comp Med. 1962;26:49-56.

7. Cartwright SF, Lucas M, Cavill PJ, Gush AF, Blandford TB. Vomiting and wasting disease of piglets. Vet Rec. 1969;84:175-6.

8. Mengeling WL, Cutlip RC. Pathogenicity of field isolates of hemagglutinating encephalomyelitis virus for neonatal pigs. J Am Vet Med Assoc. 1976;168:236-9.

9. Mengeling WL. Incidence of antibody for hemagglutinating encephalomyelitis virus in serums from swine in the United States. Am J Vet Res. 1975;36:821-3.

10. Alsop JE. A presumptive case of vomiting and wasting disease in a swine nucleus herd. Journal of Swine Health and Production. 2006;14:97-100.

11. Moës E, Vijgen L, Keyaerts E, Zlateva K, Li S, Maes P, et al. A novel pancoronavirus RT-PCR assay: frequent detection of human coronavirus NL 63 in children hospitalized with respiratory tract infection in Belgium. BMC Infect Dis. 2005;5:6.

12. Sasseville AMJ, Gelidas AM, Sawyer S, Boutin M, Boutin S, Dea $\mathrm{S}$. Biological and molecular characteristic of an HEV isolate associated with recent acute outbreak of encephalomyelitis in Quebec pig farms. Adv Exp Med Biol. 2001;494:57-62.

13. Werdin RE, Sorensen DK, Stewart WC. Porcine encephalomyelitis caused by hemagglutinating encephalomyelitis virus. J Am Vet Med Assoc. 1976;168:240-6.

14. Andries K, Pensaert MB. Immunofluorescence studies on the pathogenesis of hemagglutinating encephalomyelitis virus in pigs after oronasal inoculation. Am J Vet Res. 1980;41:1372-8.

15. Narita M, Kawamura H, Tsuboi T, Haritani M, Kobayashi M. Immunopathological and ultrastructural studies on the tonsils of gnotobiotic pigs infected with strain $67 \mathrm{~N}$ of hemagglutinating encephalomyelitis virus. J Comp Pathol. 1989;100:305-12.

Address for correspondence: María A. Quiroga, Cátedra de Patología Especial, Facultad de Ciencias Veterinarias, Universidad Nacional de La Plata, calle 60 y 118, CC 296 B 1900 AVW, La Plata, Argentina; email: mquiroga@fcv.unlp.edu.ar 